\title{
Effectiveness of Acceptance and Commitment Therapy on Psychological Capital and Emotional Expression Styles in Women with Multiple Sclerosis
}

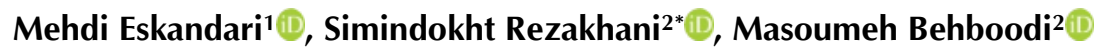 \\ 1 PhD Candidate, Department of Counseling, Roudehen Branch, Islamic Azad University, Roudehen, Iran \\ 2 Department of Counseling, Roudehen Branch, Islamic Azad University, Roudehen, Iran
}

\author{
*Corresponding author: \\ Simindokht Rezakhani, Department of \\ Counseling, Roudehen Branch, \\ Islamic Azad University, Roudehen, \\ Iran \\ Email: rezakhani@riau.ac.ir
}

Received: 13 Jul. 2020

Accepted: 16 Aug. 2020

ePublished: 01 May. 2021

\begin{abstract}
Background and Objective: Multiple sclerosis (MS) is an unpredictable and one of the most important life-altering diseases which gradually leads to disability. This study aimed to investigate the effect of acceptance and commitment therapy (ACT) on psychological capital and emotional expression styles of female patients with MS in the Iranian MS Society during 2019-2020.

Materials and Methods: The statistical population of the study consisted of all females with MS who were members of the Iranian MS Society in 2019. In total, 36 patients were selected voluntarily who were randomly divided into three groups (ACT, placebo, and control). The intervention was held in eight 90-min weekly sessions for the intervention and the placebo groups at the office of the Iranian MS Society, Tehran, Iran. All groups were re-evaluated at the end of the intervention and also two months later (i.e., follow-up stage). The obtained data were analyzed using repeated-measures analysis of variance.

Results: Based on the results, ACT affected the components of hope and resilience at the significance level of 0.01 and the components of self-efficacy and optimism at the significance level of 0.05, compared to the control group. Moreover, the ACT was able to increase the components of hope and resilience at the significance level of 0.01 and the component of optimism at the significance level of 0.05 in comparison with the placebo group.

Conclusions: The ACT increased psychological capital components, including hope, optimism, resilience, and self-efficacy in patients with MS.

Keywords: Acceptance and commitment therapy, Emotional expression styles, Multiple sclerosis, Psychological capitals
\end{abstract}

\section{Background}

Health is one of the most important aspects of life [1] and one of the important categories in the discussion of health is paying attention to the type and severity of the disease [2,3]. Multiple sclerosis (MS) is a chronic disease of the central nervous system that affects sensory and motor function [4] and is associated with periods of worsening in 85$90 \%$ of patients $[5,6]$. Symptoms of the disease exacerbation are a clinical reflection of increased inflammatory activity in the central nervous system [7]. These periods of progression with the unknown prognosis of the disease are a major challenge for patients [8].

MS is the third leading cause of disability in the world [9], affecting approximately 2.5 million people worldwide [10]. There are no accurate statistics on the number of patients with this disease in Iran [11]; nevertheless, according to the experts of the MS Association, about 5,000 new cases of this disease are identified annually in Iran [2], which is 2.8 to 3.6 times more prevalent in females, compared to males [12]. However, there is no definitive treatment for this disease [13] and the existing treatment methods cause a wide range of unpleasant symptoms [7]. These effects, in turn, affect the mental health of women and have many profound effects on their lives. Many of these patients experience communication problems in their lives and are led to depression, which is due to the low psychological capital of these patients $[14,15]$.

Psychological capital is a positive psychological state which provides a realistic and flexible approach to life [16] that consists of four structures, namely hope, optimism, resilience, and self-efficacy $[17,18]$. It must be noted that each structure is defined as a positive psychological capacity [19] that has a valid measurement scale, is based on theory and research, is state-dependent, is able to grow, and has a significant relationship with functional outcomes (20). Psychological capital is considered to be a higher-order structure [20] that includes one's self- 
perception, goals to achieve success, and endurance in the face of problems. It leads to the expression of emotions and is low in chronic patients [21,22].

Psychological capital means to be confident to make the necessary effort to succeed in challenging situations, have a positive outlook on success in the present and the future, have the perseverance to move toward one's goals or changing goals to achieve success, and show self-resistance in the face of problems and hardships and accept them (28). According to previous studies, emotional empowerment makes it easier to face life challenges and helps people achieve mental health [23]. People with emotional health can recognize their feelings and express them to others in an appropriate manner [24].

Given the above, the psychological capital and emotion expression styles in patients, especially the chronically ill, are lower than in healthy individuals, and there is a need for treatment to increase these variables. Given the nature of acceptance and commitment therapy (ACT), it can be used to fulfill this purpose. It is a cohesive treatment system based on the way all human beings consciously communicate with each other and the world around them [25].

\section{Objectives}

This study aimed to investigate the effectiveness of ACT on psychological capital and emotional expression styles of females with MS.

\section{Materials and Methods}

This quasi-experimental study was conducted based on a pre-test and post-test design with a two-months follow-up period and a control group. The study population consisted of all women with MS who were a member of Iranian MS Society in 2019. In total, 36 female patients were selected voluntarily who were randomly divided into three groups (ACT, placebo, and control groups). The inclusion criteria in the study were age range of 25-45 years, the passage of at least three months since their diagnosis, passage of at least three months since the beginning of their medical treatment, and education level of at least third grade of elementary school. The exclusion criteria included lack of a mental illness, use of psychiatric medications, and use of psychological services. The subjects were assessed before and after the intervention with the Luthans Psychological Capital Questionnaire and the Ammons and King Emotional Expression Questionnaire.

Luthans Psychological Capital Questionnaire This questionnaire was designed by Luthans, Olivier, Avi, and Norman in 2007 and includes four subscales of hope, resilience, self-efficacy, and optimism. In a research performed by Luthans and Olivo, the Cronbach's alphas of the subscales of this questionnaire were calculated at $0.88,0.89,0.89$, and 0.89 , respectively [26].

In a study performed by Ghane Sang-e-Atash, Mirzazadeh, Azimzadeh, and Abdolmaleki, the validities of the subscales of self-efficacy, hope, resilience, and optimism and the whole scale were calculated by Cronbach's alpha at 0.676, 0.738, $0.705,0.786$, and 0.84 , respectively. The four factors obtained in total can account for $61.72 \%$ of the variance, which indicates the construct validity of the questionnaire [27].

Ambivalence over Emotional Expression Questionnaire

This questionnaire was developed by Ammons and King in 1990 and has 28 items. It has a high internal consistency. The Cronbach's alphas of the whole questionnaire and the subscales of ambivalence in expressing positive and negative emotions were $0.89,0.87$, and 0.77 , respectively. Moreover, its testretest reliability value was 0.78 after six weeks, which is considered good [28].

In Iran, Alavi et al. examined the psychometric properties of this questionnaire. In the exploratory factor analysis, five questions were omitted, resulting in a 23-item version. Accordingly, 10 and 13 statements about the ambivalence in expressing positive and negative emotions, respectively. Cronbach's alpha for the first, second, and total factor was reported as $0.82,0.77$, and 0.86 , respectively. In examining the criterion validity of the questionnaire, the correlation of this questionnaire with the Beck Depression Inventory (0.35) and Social Panic (43) was calculated [29].

Data analysis was performed using descriptive and inferential statistics. The descriptive statistics section included the demographic information and statistics of the central index (mean) and dispersion index (standard deviation). In the inferential statistics section of data analysis, after confirming the existence of hypotheses using parametric tests, repeated measures analysis of variance was used to eliminate the effect of the pretest. Furthermore, the adjusted means of the studied groups were compared with each other.

\section{Results}

Based on the findings, the mean values of the disease duration for the participants in the ACT, placebo, and control groups were 6.62 \pm 11.00 , $9.08 \pm 7.58$, and $7.10 \pm 3.14$, respectively. According to the results of the Shapiro-Wilk test, the self-efficacy component in the ACT group at the follow- up 
Table 1. Significant comparison of the interactive effect of group 4 time in two groups

\begin{tabular}{|c|c|c|c|c|c|c|c|c|c|c|c|c|}
\hline & $\begin{array}{l}\text { Compared } \\
\text { groups }\end{array}$ & $\begin{array}{c}\text { Total } \\
\text { squares }\end{array}$ & $\begin{array}{l}\text { Degrees of } \\
\text { freedom }\end{array}$ & $F$ & $\mathbf{p}$ & $n^{2}$ & & $\begin{array}{c}\text { Total } \\
\text { squares }\end{array}$ & $\begin{array}{l}\text { Degrees of } \\
\text { freedom }\end{array}$ & $\mathbf{F}$ & $\mathbf{p}$ & $n^{2}$ \\
\hline \multirow{3}{*}{$\begin{array}{l}\text { Self- } \\
\text { efficacy }\end{array}$} & $\begin{array}{c}\text { ACT and } \\
\text { placebo groups }\end{array}$ & 14.97 & $\begin{array}{c}27.20 \\
1.36\end{array}$ & 1 & 0.356 & 0.047 & \multirow{3}{*}{ Resilience } & 76.17 & 2,40 & 5.19 & 0.010 & 0.206 \\
\hline & $\begin{array}{l}\text { ACT and control } \\
\text { groups }\end{array}$ & 51.10 & $\begin{array}{l}22.72 \\
1.27\end{array}$ & 33.68 & 0.047 & 0.169 & & 10.23 & 21,36 & 10.91 & 0.001 & 0.377 \\
\hline & $\begin{array}{l}\text { Placebo and } \\
\text { control groups }\end{array}$ & 14.43 & $\begin{array}{l}35.70 \\
1.78\end{array}$ & 2.62 & 0.103 & 0.076 & & 5.03 & 2,40 & 0.39 & 0.672 & 0.019 \\
\hline \multirow{3}{*}{ Hope } & $\begin{array}{c}\mathrm{ACT} \text { and } \\
\text { placebo groups }\end{array}$ & 165.87 & $\begin{array}{c}35.70 \\
1.78\end{array}$ & 13.60 & 0.001 & 0.405 & \multirow{3}{*}{ Optimism } & 91.81 & $\begin{array}{c}27.36 \\
1.37\end{array}$ & 4.51 & 0.032 & 0.184 \\
\hline & $\begin{array}{l}\text { ACT and control } \\
\text { groups }\end{array}$ & 168.23 & $\begin{array}{c}30.63 \\
1.70\end{array}$ & 11.97 & 0.001 & 0.399 & & 67.30 & $\begin{array}{l}33.34 \\
1.85\end{array}$ & 3.55 & 0.043 & 0.165 \\
\hline & $\begin{array}{l}\text { Placebo and } \\
\text { control groups }\end{array}$ & 2.47 & $\begin{array}{c}34.07 \\
1.10\end{array}$ & 0.32 & 0.69 & 0.016 & & 1.26 & $\begin{array}{c}30.72, \\
1.54\end{array}$ & 0.06 & 0.905 & 0.003 \\
\hline
\end{tabular}

stage was significant at the level of 0.05 . This indicates the non-normal distribution of the components in the aforementioned group and stage; nevertheless, considering the significance level of the Shapiro-Wilk test, it can be said that the deviation from the assumption is not severe and this issue can be ignored.

The result of the Leven test also showed that the difference in the variance of scores related to the four components of psychological capital is not significant at the level of 0.05 . This suggests that the assumption of homogeneity of variance is established among the psychological capital data. The hypothesis of independence of the dependent variable at the pre-test stage of group membership was also compared using multivariate analysis of variance. It showed that the $\mathrm{F}$ value $(\mathrm{P}<0.05, \mathrm{~F}$ $(141$ and 16) $=0.966)$ was not significant at the level of 0.05 . Therefore, the presumption of independence of the pre-test variable from group membership was also established for data related to psychological capital.

According to Table 1, ACT affected the components of hope $(\mathrm{F}(30.63$ and 1.70) $=11.97)$ and resilience $(\mathrm{F}$ (36 and 2) =10.91) at the significance level of 0.01, compared to the control group. Moreover, it was able to affect the components of self-efficacy ( $F$ $(22.72$ and 1.27$)=3.68)$ and optimism $(\mathrm{F}(33.34$ and $1.85)=3.55)$ at the significance level of 0.05 , compared to the control group. Table 1 also shows that ACT has caused an increase in the component of hope $(\mathrm{F}(35.70$ and 1.78) $=13.60)$ and resilience $(\mathrm{F}$ $(40$ and 2$)=5.19)$ at the significance level of 0.01 and the component of optimism (F (27.36 and 1.37)
$=4.51)$ at the significant level of 0.05 , compared to the placebo group. Therefore, in the first hypothesis test, it was concluded that ACT was able to significantly increase the mean value of psychological capital components in patients with MS.

The Shapiro-Wilk index of the negative emotion ambivalence is significant at the level of 0.05 in the ACT group. Given the significant level of the Shapiro-Wilk index, this does not invalidate the results. In addition, based on the results of multivariate analysis of variance, before the implementation of independent variables, there was no significant difference between the groups in terms of dimensions of ambivalence $(\mathrm{P}<0.05, \mathrm{~F}(96$, $8)=561)$. Therefore, it was concluded that the assumption of independence of the pre-test variable from group membership is also valid for the dimensions of ambivalence.

According to Table 2, the ACT reduced the positive emotion ambivalence (F (32.09 and 1.78) =5.08) and negative emotion ambivalence (F (22.36 and $1.24)=63.22)$ at a significant level of 0.05 , compared to the control group. Furthermore, the ACT caused a decrease in positive emotion ambivalence (F (31.42 and 1.57) =7.89) and negative emotion ambivalence (F (27.97 and 1.40) $=7.26)$ at a significance level of 0.01 in comparison with the placebo group. Hence, it can be said that ACT significantly reduced the mean scores of the ambivalent components at the post-test and followup stages compared to the control and placebo groups. Therefore, in testing the second hypothesis, it was concluded that ACT significantly reduces ambivalence in patients with MS.

Table 2. Significant comparison of the interactive effect of group 4 time in two groups on the dimensions of ambivalence

\begin{tabular}{|c|c|c|c|c|c|c|c|c|c|c|c|c|}
\hline & $\begin{array}{l}\text { Compared } \\
\text { groups }\end{array}$ & $\begin{array}{c}\text { Total } \\
\text { squares }\end{array}$ & $\begin{array}{l}\text { Degrees } \\
\text { of } \\
\text { freedom }\end{array}$ & $\mathbf{F}$ & p & $\mathrm{n}^{2}$ & & $\begin{array}{c}\text { Total } \\
\text { squares }\end{array}$ & $\begin{array}{c}\text { Degrees } \\
\text { of } \\
\text { freedom }\end{array}$ & $\mathbf{F}$ & $\mathbf{p}$ & $\mathrm{n}^{2}$ \\
\hline \multirow{3}{*}{$\begin{array}{l}\text { Positive } \\
\text { emotion } \\
\text { ambivalence }\end{array}$} & $\begin{array}{c}\text { ACT and } \\
\text { placebo groups }\end{array}$ & 91.86 & $\begin{array}{c}31.42, \\
1.57\end{array}$ & 7.89 & 0.001 & 0.283 & \multirow{3}{*}{$\begin{array}{c}\text { Negative } \\
\text { emotion } \\
\text { ambivalence }\end{array}$} & 87.75 & $\begin{array}{c}27.97 \\
1.40\end{array}$ & 7.26 & 0.006 & 0.266 \\
\hline & $\begin{array}{c}\text { ACT and } \\
\text { control groups }\end{array}$ & 50.63 & $\begin{array}{c}32.09 \\
1.78\end{array}$ & 55.08 & 00.015 & 00.220 & & 91.43 & $\begin{array}{c}22.36 \\
1.24\end{array}$ & 5.63 & 0.021 & 0.238 \\
\hline & $\begin{array}{l}\text { Placebo and } \\
\text { control groups }\end{array}$ & 6.84 & $\begin{array}{c}39.32 \\
1.97\end{array}$ & 51.05 & 00.360 & 00.050 & & 15.53 & $\begin{array}{c}36.75 \\
1.84\end{array}$ & 1.87 & 0.171 & 0.086 \\
\hline
\end{tabular}




\section{Discussion}

Based on the results, the ACT affected the components of hope and resilience of psychological capital at the significance level of 0.01 and the components of self-efficacy and optimism at the significance level of 0.05 in comparison with the control group. Furthermore, the ACT increased the components of hope and resilience of psychological capital at the significance level of 0.01 and the component of optimism at the significance level of 0.05 , compared to the placebo group.

In other words, in the ACT group, unlike the control and placebo groups, the mean scores of components of psychological capital increased at the post-test stage, compared to the pre-test stage, and remained the same at the follow-up stage. Therefore, it can be said that ACT was able to increase psychological capital, including hope, optimism, resilience, and self-efficacy, in patients with MS. The results of this study are in line with those of the studies performed by Mohammadi (2016), Barghi Irani et al. (2015), Baghban Baghestan et al. (2017), and Jeloudari et al. (2009).

In general, acceptance and commitment therapists encourage the clients to recognize the psychological content and reduce their struggles with them and be more accepting to be able to move in a valuable direction (Barghi Irani et al., 2015).

In this regard, since MS is a progressive disease with an unknown initial cause, the patients might think about why they have this disease. When people are constantly engrossed in their questioning mindsets and worry about the future, they find themselves experiencing unpleasant situations and try to find a way to escape from them. Hence, the life of the patient tends to become more and more limited.

Given that the study population is women who have undergone at least three months of medical treatment, ACT may be able to help them increase their resilience by accepting what cannot be changed and creating a new perspective. Moreover, it helps them gain a new perspective towards life by increasing optimism and emphasizing the things that are in one's control and increases one's selfefficacy. In addition, it gives them hope to move towards a life worth living through the development of a well-written plan for their journey. It seems that the increase of psychological flexibility, which is the main goal of ACT, will help individuals have a higher level of acceptance or resilience in the face of psychological problems. Moreover, it will help them not to give up and seek active action by creating hope, self-efficacy, and a positive and optimistic outlook on the future.

Emotions always affect attention, decision-making abilities, memory, physiological responses, social interactions, and even a wide range of interpersonal and intrapersonal processes. According to King and Ammons (2006), emotional empowerment and the ability to express emotions makes it easier to face challenges in life.

Emotional health is one of the aspects of mental health that requires the expression of emotions. People with desirable emotional expression styles know their emotions and can express them in an appropriate manner. From the point of view of ACT, people are always trying to move towards a valuable life, and one of the serious obstacles in the way is the lack of expression of emotions in the correct way. One of the basic techniques of this method of treatment is confrontation which is used to confront people with their inner selves to identify their inner emotions and express them to move towards the values.

Therefore, it seems that learning to be accepting in life and having a level of commitment to move towards values lead people towards being aware of their inner emotions and experiencing them instead of ignoring them. Hence, ACT helps patients with MS to adopt a new outlook on life and have a better interaction with their inner selves.

This research had several limitations; for instance, the sample group was selected voluntarily. Therefore, non-random selection of individuals in the sample group can affect the validity of the research. Moreover, various factors, such as family status and relationships, social support, economic status, and cultural factors might have affected the treatment process of the sample group and, in turn, the results of the research. It must be noted that these factors were beyond the control of the researcher. Finally, considering that the sample group consisted of women with MS, the findings of the present study do not apply to the males and females with MS who do not meet the inclusion criteria of this research.

Findings of the study indicated the effectiveness of ACT on the psychological capital of people with MS. Therefore, psychologists and counselors working in the MS Association and all counselors and psychologists who deal with this disease are recommended to use the above-mentioned treatment methods to increase the psychological capital of individuals. Besides, due to the effects of AC'T on changing the emotional expression styles of patients with MS, psychologists and counselors are recommended to use this treatment to help their patients in this regard.

\section{Conclusions}

The results showed that ACT compared to the control group reduced ambivalence in expressing 
positive and negative emotions to a significant level of 0.05 . This treatment has been able to reduce ambivalence in expressing positive and negative emotions to a significant level of 0.01 . In this regard, ACT has reduced the scores of the ambivalence components in the post-test and follow-up stages compared to the control and placebo groups.

\section{Compliance with ethical guidelines}

Before conducting the study, ethical and institutional approval was obtained from the Ethics Committee of the Islamic Azad University of Medical Sciences, Tehran Branch, Iran (IR.IAU.TMU.REC.1398.084). All the ethical principles were respected in this study; accordingly, the participants were informed about the purpose of the study and implementation of the stages. In addition, informed consent was obtained from all the study subjects. The patients were also assured of the confidentiality of their information. Moreover, the subjects were informed that they were free to withdraw from the study at any time and the results would be available to them if desired.

\section{Acknowledgments}

The authors would like to express their gratitude to the participants who greatly cooperated in the conduction of this study. They would also like to thanks the Iranian MS Society for their help throughout the project.

\section{Authors' contributions}

Conceptualization: Mehdi Eskandari; methodology: Simindokht Rezakhani; investigation: Mehdi Eskandari; writing the original draft: all authors; writing, reviewing, and editing: all authors; funding acquisition: all authors; resources: all authors; contribution to the final version: Masoumeh Behboodi; supervision: Simindokht Rezakhani.

\section{Funding/Support}

This research did not receive any specific grant from funding agencies in the public, commercial, or not-for-profit sectors.

\section{Conflicts of Interest}

The authors declare that they have no conflict of interests.

\section{References}

1. Cantorna MT. Mechanisms underlying the effect of vitamin D on the immune system. The Proceedings of the Nutrition Society. 2010; 69(3):286-9. [DOI:10.1017/S00296651100 01722] [PMID] [PMCID]

2. Kurtzke JF. Rating neurologic impairment in multiple sclerosis: an expanded disability status scale (EDSS). Neurology. 1983; 33(11):1444-52. [DOI:10.1212/WNL.33.11.1444] [PMID]

3. Smolders J, Menheere P, Kessels A, Damoiseaux JG, Hupperts R. Association of vitamin D metabolite levels with relapse rate and disability in multiple sclerosis. Multiple Sclerosis Journal. 2008; 14(9):1220-4. [DOI:10.1177/1352458508094399] [PMID]

4. Salzer J, Hallmans G, Nystrom M, Stenlund H, Wadell G, Sundstrom P. Vitamin D as a protective factor in multiple sclerosis. Neurology. 2012; 79(21):2140-5. [DOI:10.1212/ WNL.0b013e3182752ea8] [PMID]

5. Ascherio A. Environmental factors in multiple sclerosis. Expert Review of Neurotherapeutics. 2013; 13(12 Suppl):39. [DOI: 10.1586/14737175.2013.865866] [PMID]

6. Niino M, Miyazaki Y. Vitamin D in multiple sclerosis. Brain and Nerve. 2015; 67(11):1429-33. [DOI:10.11477/mf.1416 200316] [PMID]

7. Islam T, Gauderman WJ, Cozen W, Mack TM. Childhood sun exposure influences risk of multiple sclerosis in monozygotic twins. Neurology. 2007; 69(4):381-8. [DOI: 10.1212/01.wnl.0000268266.50850.48] [PMID]

8. Jumah MA, Kojan S, Khathaami AA, Abdulkaream IA, Blawi MA, Jawhary A. Familial multiple sclerosis: does consanguinity have a role? Multiple Sclerosis Journal. 2011; 17(4):487-9. [DOI:10.1177/1352458510390406] [PMID]
9. Mackenzie IS, Morant SV, Bloomfield GA, MacDonald TM, O'riordan J. Incidence and prevalence of multiple sclerosis in the UK 1990-2010: a descriptive study in the General Practice Research Database. Journal of Neurology, Neurosurgery \& Psychiatry. 2014; 85(1):76-84. [DOI:10.1136/jnnp-2013305450] [PMID] [PMCID]

10. McDonald WI, Compston A, Edan G, Goodkin D, Hartung $\mathrm{HP}$, Lublin FD, et al. Recommended diagnostic criteria for multiple sclerosis: guidelines from the International Panel on the diagnosis of multiple sclerosis. Annals of Neurology: Official Journal of the American Neurological Association and the Child Neurology Society. 2001; 50(1):121-7. [DOI:10.1002/ana.1032] [PMID]

11. Poser CM, Paty DW, Scheinberg L, McDonald WI, Davis FA, Ebers GC, et al. New diagnostic criteria for multiple sclerosis: guidelines for research protocols. Annals of Neurology. 1983; 13(3):227-31. [DOI:10.1002/ana.4101 30302] [PMID]

12. Josey L, Curley M, Jafari Mousavi F, Taylor BV, Lucas R, Coulthard A. Imaging and diagnostic criteria for M ultiple $\mathrm{S}$ clerosis: are we there yet? Journal of Medical Imaging and Radiation Oncology. 2012; 56(6):588-93. [DOI:10.1111/j. 1754- 9485.2012.02448.x] [PMID]

13. Ramagopalan SV, Handel AE, Giovannoni G, Rutherford Siegel S, Ebers GC, Chaplin G. Relationship of UV exposure to prevalence of multiple sclerosis in England. Neurology. 2011; 76(16):1410-4. [DOI:10.1212/WNL.0b013e31821 6715e] [PMID] [PMCID]

14. Sadovnick AD. Differential effects of genetic susceptibility factors in males and females with multiple sclerosis. Clinical Immunology. 2013; 149(2):170-5. [DOI:10.1016/j.clim.2013. 05.002] [PMID]

15. Lau KK, Wong WW, Sheng B, Yu IT, Fung BH, Li HL, et al. The clinical course of multiple sclerosis patients in Hong Kong. Journal of the Neurological Sciences. 2008; 268(12):78-82. [DOI:10.1016/j.jns.2007.11.006] [PMID]

16. Farez MF, Aguirre ME, Varela $F$, Kuhler AA, Nagel $V$, Correale J. Low familial risks for multiple sclerosis in Buenos Aires, Argentina. Journal of the Neurological Sciences. 2014; 346(1-2):268-70. [DOI:10.1016/j.jns.2014.09.004] [PMID]

17. Munger KL, Zhang SM, O'reilly E, Hernan MA, Olek MJ, Willett WC, et al. Vitamin D intake and incidence of multiple sclerosis. Neurology. 2004; 62(1):60-5. [DOI:10.1212/01. WNL.0000101723.79681.38] [PMID]

18. Etemadifar M, Maghzi AH. Sharp increase in the incidence and prevalence of multiple sclerosis in Isfahan, Iran. Multiple Sclerosis Journal. 2011; 17(8):1022-7. [DOl:10.1177/135 2458511401460] [PMID]

19. Busrnhielm M, Olsson T, Alfredsson L. Fatty fish intake is associated with decreased occurrence of multiple sclerosis. Multiple Sclerosis Journal. 2014; 20(6):726-32. [DOI: 10.1177/1352458513509508] [PMID]

20. Orton SM, Wald L, Confavreux C, Vukusic S, Krohn JP Ramagopalan SV, et al. Association of UV radiation with multiple sclerosis prevalence and sex ratio in France. Neurology. 2011; 76(5):425-31. [DOI:10.1212/WNL. Ob013e31820a0a9f] [PMID] [PMCID]

21. Munger KL, Levin LI, Hollis BW, Howard NS, Ascherio A Serum 25-hydroxyvitamin D levels and risk of multiple sclerosis. JAMA. 2006; 296(23):2832-8. [DOI:10.1001/jama. 296.23.2832] [PMID]

22. Zhang SM, Willett WC, Hernбn MA, Olek MJ, Ascherio A Dietary fat in relation to risk of multiple sclerosis among two large cohorts of women. American Journal of Epidemiology. 2000; 152(11):1056-64. [DOI:10.1093/aje/152.11.1056] [PMID]

23. Roxburgh RH, Seaman SR, Masterman T, Hensiek AE, Sawcer SJ, Vukusic S, et al. Multiple Sclerosis Severity Score: using disability and disease duration to rate disease severity. Neurology. 2005; 64(7):1144-51. [DOI:10.1212/01.WNL. 0000156155.19270.F8] [PMID]

24. Lonergan R, Kinsella K, Fitzpatrick P, Brady J, Murray B, Dunne $C$, et al. Multiple sclerosis prevalence in Ireland: relationship to vitamin D status and HLA genotype. Journal of Neurology, Neurosurgery \& Psychiatry. 2011; 82(3):31722. [DOI:10.1136/jnnp. 2010.220988] [PMID]

25. McFarlin DE, McFarland HF. Multiple sclerosis. New 
England Journal of Medicine. 1982; 307(20):1246-51. [DOI:10.1056/NEJM198211113072005] [PMID]

26. Luthans F, Avolio BJ, Avey JB, Norman SM. Positive psychological capital: Measurement and relationship with performance and satisfaction. Personnel Psychology. 2007; 60(3):541-72. [DOI: 10.1111/j.1744-6570.2007.00083.x]

27. Ghane Sangatash A, Mirzazadeh Z, Azimzadeh S, Abdolmaleki $\mathrm{H}$. The role of psychological capital on social capital of Physical Education Students of Mashhad Universities. Applied Research in Sport Management. 2016; 4(3):91-106.

28. King LA, Emmons RA. Conflicts over emotional expression: psychological and physical correlates. Journal of Personality and Social Psychology. 2006; 58(5):864-77. [DOI:10.1037// 0022-3514.58.5.864] [PMID]

29. Alavi K, Asghari Moghadam MA, Rahiminezhad A, Farahani H. Psychometric properties of Ambivalence over Emotional
Expression Questionnaire. Journal of Research in Psychological Health. 2017; 11(1):74-91. [DOI: 10.29252/rph.11.1.74]

30. Mohammadi Z. The effectiveness of acceptance and commitment-based therapy on the psychological capital of MS patients with BIS and BAS (behavioral brain systems) personality type. [Master Thesis]. Tehran: Payame Noor University; 2016.

31. Baghban Baghestan A, Aerab Sheibani KH, Javedani Masrur $M$. Acceptance and commitment based therapy on disease perception and psychological capital in patients with type II diabetes. The Horizon of Medical Sciences. 2017; 23(2):135-40.

32. Jelodari S, Sodagar S, Bahrami Hidaji M. The effectiveness of Acceptance and Commitment Therapy (ACT) on psychological flexibility and cognitive emotion regulation in women with breast cancer. Journal of Applied Psychology. 2020; 13(4):527-48. [DOI:10.29252/APSY.13.4.527] 